\title{
Models and Reality: How Did Models Divorced from Reality Become Epistemologically Acceptable?
}

\author{
Asad Zaman ${ }^{\circledR}$ \\ Received: 12.12.2019 Accepted: 29.04.2020 Published: 30.04.2020
}

\begin{abstract}
Economic models translate real problems to an artificial world, and calculate outcomes. The match between artificial worlds populated by rational robots, and the real world, is never assessed. Instead, models are judged on aesthetic grounds, involving conformity to preconceived principles of optimization and equilibrium. Despite methodological proclamations to the contrary, models are not judged by predictive performance. Economics models are formulated axiomatically, and never cross-checked against reality. Taking this (controversial) characterization of economic methodology for granted, this paper sketches trends in philosophy of science which led to a methodology which permits creation of mental models disconnected from reality. A key development was the separation of the observable phenomena from the underlying reality (noumena) which eventually allowed empiricist philosophers to jettison the underlying reality as part of what good models attempt to describe. The paper discusses contemporary methodologies for assessing models in economics and econometrics, and explains why these lead to models disconnected from reality.
\end{abstract}

Key words: Empiricism, Logical Positivism, Critical Realism, Economic Methodology JEL Classifications: B4

\section{FROM SURROGATE TO SUBSTITUTE MODELS}

The problem at the heart of modern economics is buried in its logical positivist foundations created in the early twentieth century by Lionel Robbins. Substantive debates and critiques of the content actually strengthen the illusion of validity of these methods, and hence are counterproductive. As Solow said about Sargent and Lucas, you do not debate cavalry tactics at Austerlitz with a madman who thinks he is Napoleon Bonaparte, feeding his lunacy. Modern macroeconomic models are based assumptions representing flights of fancy so far beyond the pale of reason that Romer calls them "post-real". But the problem does not lie in the assumptions - it lies deeper, in the methodology that allows us to nonchalantly make and discuss crazy assumptions. The license for this folly was given by Friedman (1953, reproduced in Mäki, 2009a): "Truly important and significant hypotheses will be found to have 'assumptions' that are wildly inaccurate descriptive representations of reality". In this article, I sketch an explanation of how economic methodology went astray in the 20th Century, abandoning empirical evidence in favor of mathematical elegance and ideological purity. Many

\footnotetext{
${ }^{\circledR}$ Asad Zaman, External Member of Monetary Policy Committee of State Bank of Pakistan and Director Social Sciences, Al-Nafi Online Educational Platform (email: asad.zaman@alumni.stanford.edu)

I would like thank Alan Hájek for his stimulating and insightful comments, Edward Fullbrook for encouragement, and Lars Syll for his help in finding useful quotations to buttress my arguments. This paper has also been published in Real World Economics Review, Issue 91, March 2020.
} 
authors have noted this problem - for instance, Krugman writes that the profession (of economists) as a whole went astray because they mistook the beauty of mathematics for truth.

To begin with, it is important to understand that modern economics is entirely based on models. There is a lot of merit to the idea that economic knowledge must be encapsulated in models. This is because economic systems are complex and interactive. We may well have strong intuitions about some local aspects of the system, but when we put all our intuitions about the different parts together, something unexpected may emerge. This is now well known as the phenomenon of complexity, and emergent behavior. This also explains the central importance of mathematics in modern economics. When we want to piece together parts of a complex system into a whole, mathematics is necessarily and inevitably involved, because the required integration cannot be done intuitively and qualitatively. The central hypothesis which drives this paper is that the relationship between economic models and reality shifted over the course of the 20th century. The nature of this shift can be described by borrowing some insightful terminology from Mäki (2018). He defines two types of models. One is a surrogate model: such a model is a simplification which attempts to match some complex reality, and can be judged by the degree of resemblance it achieves. The second type is a substitute model: the imagined mini world of the model is a substitute for the target maxi real world, rather than an attempt to approximate the latter. As Mäki (2018) notes: "surrogate models can be wrong (or right), while substitute models cannot even be wrong about the world (since they are not presented and examined as being about the world)." Our main thesis in this paper is that economists started to use models as surrogates, but eventually fell in love with their own creations, and began to treat them as substitutes for the real thing. The goal of this paper is to sketch how and why this happened.

\section{A MIDDLE-BROW HISTORY OF METHODOLOGY}

Our goal in this essay in NOT to add to the debunking of economics - this task has been done in many books and essays, and the debunking has been contested by many other books and essays. A balanced state of the art survey is available in Uskali Mäki (2002) who opens the book with:

"Fact or fiction? Is economics a respectable and useful reality-oriented discipline or just an intellectual game that economists play in their sandbox filled with imaginary toy models? Opinions diverge radically on this issue, which is quite embarrassing from both the scientific and the political point of view."

Instead of joining this debate, we take the second option as a given: economics is an intellectual game that economist play with toy models. We are interested in the meta-question of how did this become possible? What are the trends in history of thought which allowed the development of models completely divorced from reality?

A book length detailed treatment of the answer to this question has been provided by Manicas (1987) in "A history and philosophy of the social sciences." The central thesis of this "embarrassingly ambitious" book challenges the very notion of "social science", suggesting that it was built on the wrong foundations. A very brief outline of the central ideas of this book is as follows.

1. The practices of the modern sciences which emerged in the sixteenth and seventeenth centuries were incorrectly characterized. For various historical reasons, this remained 
unrecognized in the more refined and sophisticated 'philosophies' of science which subsequently came to be articulated.

2. Social sciences took their modern shape in the early 20th Century as the result of a deliberate attempt to apply the "scientific method" to the production of knowledge about human societies. But the understanding of the scientific method was deeply flawed. As a result, the "methodology" adopted for use in social science was also deeply flawed.

According to Manicas, "The upshot is the possibility of a thoroughgoing revolution in the received ideas of science, natural and social. It allows us to ask whether there is a huge gap between the ideology of science and practices in the physical sciences, and whether, more disastrously, the social sciences have been ideologically constituted in the sense that they were based on a misconception about what the physical sciences are."

In a commentary on Rodrik's (2015) defence of economic methodology, Mäki (2018) writes that "The portrait of economics offered by philosophers of economics... (is)... too refined for practicing economists, but the degree of refinement... (in understanding economic methodology)... currently held by practicing economists is often too low." The message of Manicas (1987) is central to understanding current methodology of social science, and leads to the possibility of a thoroughgoing revolution. However, reading and understanding this book requires background in history and philosophy which very few economists have. As a partial remedy, I have attempted to provide a coarse-grained and crude summary of some of the highbrow philosophical ideas which have driven the development of methodologies in the social sciences in general, and economics in particular. The goal is to explain how it became possible to think that it is reasonable to develop models without connecting them to external real world structures. We begin with a rough description of what this methodology is, based on an experiential view, rather than a theoretical perspective.

\section{THE METHODOLOGY OF ECONOMICS}

What is the methodology economists use to arrive at knowledge about the economic system, used to analyze, explain, and decide upon policy? This question is not as easy as it appears on the surface for a number of reasons. The problem in understanding methodology comes from the easily documented fact that the justifications offered for methodology, the textual explanation of the methodology, the actual practice, and what we economists think we are doing, are all different. Mäki (2002) is an anthology of an extensive discussion from diverse viewpoints on the extent to which economic knowledge is fictional or factual. The goal of this essay is not an in-depth exploration of methodology. In order to cut through confusion, I will take a practitioners' approach, namely, the methodology that I learned as a graduate student, and adopted in my own research. This "experiential" or folk-methodology, is full of incoherent and contradictory elements. In a gentle critique of Rodrik's defense of economic methodology, Mäki (2018) concludes as follows: "Economists are desperately in need of a better selfunderstanding, a more adequate portrait of their discipline, including its methods of modelling." As students, we arrive at a very clear, explicit, and detailed understanding of economic practice, as it is exposited by textbooks and teachers. Reflections of methodology are discouraged, because we know exactly what we are doing, and methodological discussions seem hopelessly ambiguous, imprecise, and unrelated to the work of producing good economic models. It is precisely because of this lack of reflection that incoherent and inconsistent methodological approaches continue to dominate the profession. The folk-methodological principles outlined 
below are part of what I and fellow graduate students and later, colleagues in Economics Departments learned, used, and taught, often without explicit articulation.

\subsection{Baconian Science}

Without much reflection or discussion, we are trained to think of Science in Baconian terms. Scientific laws are obtained by induction from a pattern of observations. Deeper discussions on whether we need induction, or "abduction" to the best explanation never take place. There is general positivist outlook which suggests that "unobservables" should be shunned in scientific theories. No one seems to be aware that, due to developments in physics, the positivists themselves had moved on to much more sophisticated formulations of the notion of "observability" before abandoning it as a hopeless cause. In economics, we continue to use unobservable and observable in the primitive sense, are not aware of the philosophical difficulties that emerge on attempting to reconcile these terms with accepted theories of physics. Even more interesting, we do not even reflect on the fact that the Baconian approach is not actually followed in development of the textbook models of economics. There is no description of large amounts of empirical data which is synthesized into theories. Without discussion, students assume that this preliminary spadework has already been done, and we are studying theories which distil masses of empirical evidence, without explicit mention. In fact, this is not the case, as I learned much later. The axiomatic theories we study fly in the face of massive amount of empirical evidence uncovered by behavioral economists and psychologists, and these conflicts are routinely ignored; see Zaman and Karacuka (2012) for a survey.

\subsection{Axiomatic-Deductive Model of Science}

In the 1930's, Lionel Robbins re-constructed the foundations of economics, replacing the earlier "welfare approach" by the scarcity approach now universally adopted; see Cooter and Rapaport (1984) for details and discussion. This was parallel to efforts made throughout the social sciences to make humanities more scientific by adopting the "scientific method". Unfortunately, "scientific method" was defined as it was (mis)understood by logical positivists. According to positivists, science was based on a set of certainties (facts, and scientific laws) and logical deductions from these postulates. Lionel Robbins (1932) expressed this "received view of scientific theories" as follows: "The propositions of economic theory, like all scientific theory, are obviously deductions from a series of postulates. And the chief of these postulates are all assumptions involving in some way simple and indisputable facts of experience." This continues to be the standard understanding of what science is among economists, and provides the justification for the strongly held belief that economics is a "science." Practitioners (like myself) are blissfully unaware that this view is now dead and buried, abandoned by its most ardent defenders. For example, the opening paragraph of Suppe (2000).

"The Received View on Theories was the epistemic heart of Logical Positivism. Twelve hundred persons were in the audience the night it died. It was March 26, 1969-opening night of the Illinois Symposium on the Structure of Scientific Theories. The Received View had been under sustained attack for a decade and a critical mass of main protagonists had been assembled to fight it out. Carl Hempel, a main developer of the Received View, was the opening speaker and was expected to present the Received View's latest revision. Instead he told us why he was abandoning both the Received View and reliance on syntactic axiomatizations. Suddenly we knew the war had been won, and the Symposium became an energized exploration of where to go now." 
The article goes on to discuss the reasons for the failure of the received view, which we briefly summarize here. Positivists saw human knowledge as being encapsulated by sentences, or propositions. As per ideas of Wittgenstein, sentences were actually "pictures" of facts about the world, or logical consequences of such elementary propositions. Struggles to articulate this idea precisely failed upon detailed examination of the "correspondence rules" between sentences and events in the real world. It turned out that "correspondence rules were a heterogeneous confusion of meaning relationships, experimental design, measurement, and causal relationships some of which are not properly parts of theories". The conclusion is that scientific theory cannot be understood as a "linguistic entity" as per positivist precepts. So economic knowledge cannot be encapsulated in "propositions", as asserted by Robbins.

\subsection{The Positive-Normative Distinction}

Despite the fact that philosophers have abandoned the positive-normative distinction ever since Quine's (Willard, 1963) attack on the two dogmas of empiricism, economists continue to base methodological foundations for economics on this dichotomy. More recently, the fact/value demarcation has been successfully attacked and demolished; see Putnam (2002) for a detailed argument, or Zaman (2020) for an elementary exposition. Nonetheless, most economists only read one methodological essay in their lives, and that is Friedman's (1953) essay. In accordance with dominant and popular views at that time, Friedman presents economics as a positive science, strongly differentiated from normative ideas. This essay continues to be cited approvingly in economics textbooks, in two contexts. One is to justify assumptions which are literally false. The second is to assert that the body of economic theory is "positive": that is, it is purely objective and factual, without any appeals to subjectivity and values. Few reflect on the direct contradiction between these two widely held beliefs about economics. In contemporary textbooks, most authors are aware that the positive/normative distinction is no longer sustainable and avoid direct discussion, or appeal. However, unguarded expressions can still be found. More importantly, the realization that a large number of normative values are hidden within apparently objective axiomatic frameworks does not exist in the folkmethodology of economics. Thus, the re-thinking required by this realization has never been done. This is despite the fact that many mainstream economists have pointed out how values are involved in every aspect of economic thinking. A particularly clear demonstration is available from the book length treatment in Hausman et al. (2016). Also, Zaman (2012b) shows how three different normative principles are involved in elevating scarcity to the fundamental economic problem. Folk-methodology in economics completely ignores these issues, and treats the positive normative distinction as unproblematic. Economists continue to believe that economic theory is free of values and that values do not belong in science; see for example Hands (2012) for evidence.

\subsection{Canonical Assumptions: Optimization and Equilibrium}

Methodological writings of economists display allegiance to the Baconian view of science. It is asserted that our theories are derived from studying the world, and are "positive" - they are factual and objective descriptions of external reality, not tainted by normative ideals. In addition, it is asserted by Friedman, and repeated by countless followers, that the only valid test of theories lies in their ability to predict accurately. The implication is that if theories do not predict accurately then they should be rejected. The fact is that these methodological ideals are only for display. The actual practice pays no heed to these principles. The folk-methodology of modern economics is based solidly on two principles: optimization and equilibrium. As long as 
a model is built where all agents are maximizing some objective function, and we can calculate equilibrium outcomes, this model qualifies as a valid economic model. If a model does not obey these conditions, then it is defective. The assumptions of the model can be completely bizarre and outlandish, since Friedman (1953) provided us with a license to use such assumptions. Note that this means that we have abandoned the Baconian idea of deriving laws from observed patterns in the data. Furthermore, the predictions of the model need not have any correspondence with reality. This is despite methodological professions to the contrary. The model is judged purely by allegiance to the canonical assumptions of optimization and equilibrium. Keynes remarked that "Economists are unmoved by lack of correspondence between their theories and facts." The revolutionary insights of Keynes were rejected because they could not be fitted into an optimization and equilibrium framework. Both the SamuelsonHicks synthesis, and the more recent New Keynesian school of Macroeconomics reconcile Keynesian unemployment with the optimization and equilibrium framework by jettisoning essential aspects of Keynesian theory. This is what prompted Keynes to say that I am not a Keynesian.

More recently, Romer (2016) remarked on the lack of scientific attitude of economists: "Macroeconomic theorists ignore mere facts by feigning an obtuse ignorance." For example, in an interview with Evans and Honkapohja (2005). Sargent stated that: "But after about five years of doing likelihood ratio tests on rational expectations models, I recall Bob Lucas and Ed Prescott both telling me that those tests were rejecting too many good models." The response to conflicts with data was to stop doing tests, and resort to calibration, rather than modification of the models. It is obvious that the standards to assess "good models" are not based on predictive ability. Rather, they are based on conformity to certain theoretical predilections as well as aesthetic conventions, conveniently summarized as optimization and equilibrium. A further reason for the disconnect between models and data is the nature of economic models themselves, as we discuss next.

\subsection{Substitute Versus Surrogate Models}

Mäki (2018) makes the useful distinction between substitute and surrogate models. The methodological statements by economists support the view that economic models are surrogate models. This means that such models are built as simplifications of, and approximations to, a complex reality. Thus, the results of the model are subject to the test of comparison with actual reality. If the degree of approximation between model results and reality is found wanting with respect to some target objective, models must be modified and improved. In contrast, substitute models are ends in themselves. They are subject to internal criteria for coherence, and consistency to a set of aesthetic principles built around the core of optimization and equilibrium. More explicitly, the methodology for construction of models is described explicitly by Lucas as follows:

"Unlike anthropologists, however, economists simply invent the primitive societies we study, a practice which frees us from limiting ourselves to societies which can be physically visited as sparing us the discomforts of long stays among savages. This method of society-invention is the source of the utopian character of economics; and of the mix of distrust and envy with which we are viewed by our fellow social scientists. The point of studying wholly fictional, rather than actual societies, is that it is relatively inexpensive to subject them to external forces of various types and observe the way they react. If, subjected to forces similar to those acting on actual societies, the artificial society reacts in a similar way, we gain 
confidence that there are useable connections between the invented society and the one we really care about."

The distinction between economists and anthropologists is important here. Anthropologists study real societies while economists' study artificial societies they make up. There is no target reality we are modeling. We can freely start an article by saying let us assume our society consists of a single consumer who lives infinitely long and produces and consumes only one good. In principle, as Lucas says, and as Friedman says, models with wildly inaccurate assumptions will be tested by their predictions. In fact, our textbooks and teachers never actually carry out such tests. We start with an artificial model, an invented primitive society, deduce results, and never match them against reality. So, the last sentence in the Lucas quote above is false. No one actually checks to see if the artificial society reacts in a similar way to the actual society. In the terminology of Mäki, economics models are substitute models - they take the place of reality, and the question of comparisons, or tests by predictions does not arise. Thus, methodological practice (usually unarticulated) of economics deviates from scientific methodology in two ways. One is that our models are not derived as attempts to understand, explain, or model some target complex reality - they are constructed as artificial societies which are substitutes for this complex reality. Secondly, the results obtained are not compared with any target reality to assess validity or adequacy of our models. Internal coherence and consistency. Given that models are not derived from a study of reality, and models results are not compared to reality, there is little wonder that Ronald Coase said: "Existing economics is a theoretical system which floats in the air and which bears little relation to what happens in the real world."

Bergmann (2007) describes the disconnect between economic models and reality as follows. She explains how biologists spent thousands of hours studying dolphins to learn some principles of their behavior. In contrast, economic theories of firms are based entirely on mental considerations, without any study of firm behavior at all:

"The material about business behavior that students read about in economics textbooks, and almost all of the new theoretical material developed by mainstream professionals and published in the profession's leading journals was composed by economists who sat down in some comfortable chair and... simply made it up."

\section{THE EMPIRICIST PHILOSOPHY AND ITS ERRORS}

Manicas (1987) writes in the introduction that:

"Critical to this, in my view, is the critique of empiricism (chapter 13), not merely as an untenable philosophy of the human sciences, but as a philosophy of any science. It will be clear from part I, I hope, how developments in the eighteenth century and then in last two decades of the nineteenth century made the victory of 'empiricism' in the twentieth century such an easy one, even though, as in the philosophy of Helmholtz, there were 'realist' alternatives which fully acknowledged the Kantian (and Humean) critique of 'metaphysics'. Critical in regard to an alternative realist human science is the context and program of Marx and Engels. I argue that a crucial failure in their philosophy, fully explainable, is the absence of a clear and adequate theory of science. On the other hand, I think that it is only very recent developments which have made a fully coherent 'realist' alternative plausible. The philosophy of social science offered in chapters 13 and 
14 , then, is an attempt to assimilate the recent debate, in both the philosophy of natural science and as regards the competing conceptions of the possibility of a human science, and to provide a comprehensive sketch of such an alternative. This account draws on a variety of recent and much better developed sources. Its goal is synoptic. It is, accordingly, but a sketch or perhaps a sketch of a sketch, meant to provoke and enlarge the recent debate in philosophy of the psychology and philosophy of the social sciences"

The quote shows that "empiricism" is at the heart of the failure in constructing a valid realist philosophy of science. An invalid empiricist philosophy was then applied to construct the social sciences afresh on empiricist foundations in the early 20th with disastrous results that persist today. The detailed book length treatment provided by Manicas (1987) is presented as a sketch of a sketch, meant to provoke debate. We now propose to provide a one-page summary of some critical ideas of empiricist philosophy for an audience of economists, which may perhaps be regarded as a cartoon version of the sketch. Because of the vital importance of the task, we proceed without further apology for crude over-simplifications of subtle and sophisticated philosophies.

Rejection of authority and tradition as sources of knowledge in the Enlightenment led to the rise of Empiricist philosophy. Among the early Empiricist philosophers, David Hume combined faith in observations (facts) with a skepticism about what could not be seen. This variety of empiricism holds that observations are all that we have. We cannot penetrate through the observations to the hidden reality which generates these observations. Here is a picture which illustrates the empiricist view of the world:

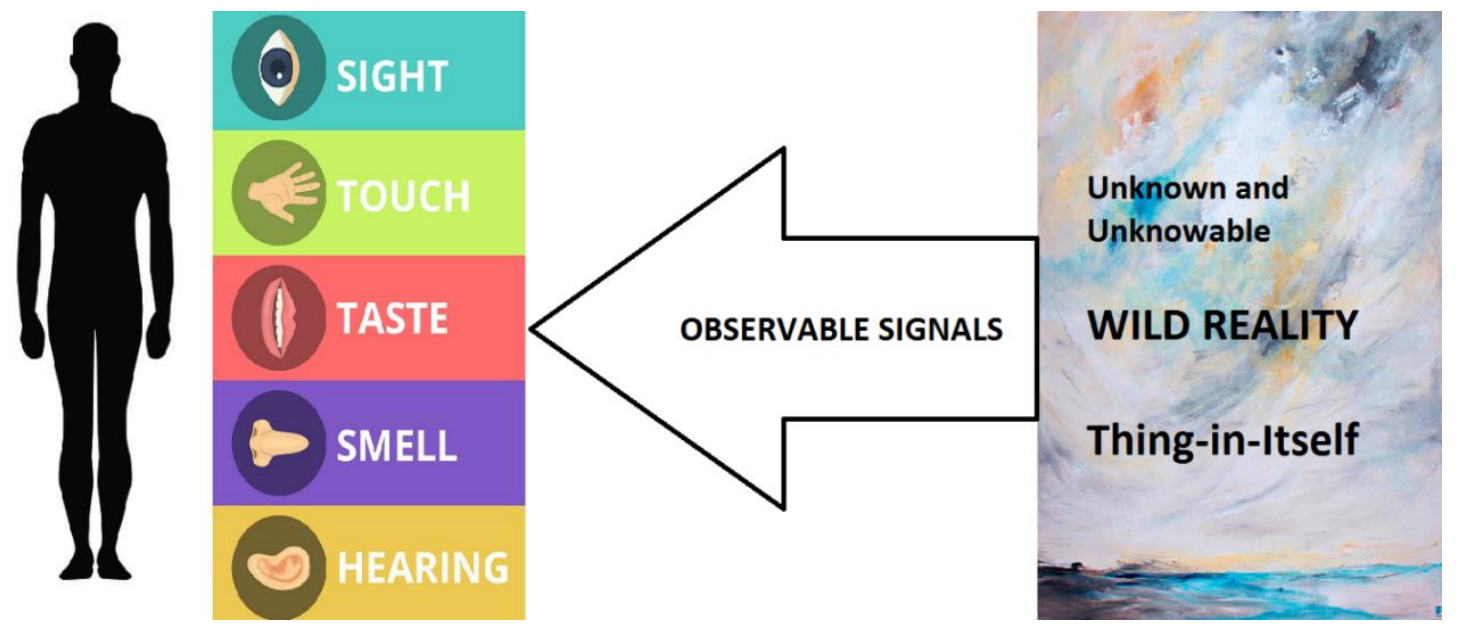

The wild and complex reality generates signals which we observe using our five senses. The aspects of reality which we can observe are the only things that we can know about reality. The true nature of hidden reality, as it really is, independent of our observations, is unknown and can never be known to us. A critical idea in the development of the theory of knowledge (epistemology) came from Immanuel Kant. Kant is a towering figure in the history of Western philosophy. His philosophy is too complex to be described in a few words, and he certainly was not an empiricist. However, he introduced some distinctions and dualisms which were extremely influential in later developments. Of importance to our arguments are the Noumena (which is the wild reality), and Phenomena (which is what we can perceive/observe about the reality). The Encyclopedia Britannica defines the terms as follows: 
Noumenon, plural Noumena, in the philosophy of Immanuel Kant, the thing-initself (das Ding an sich) as opposed to what Kant called the phenomenon-the thing as it appears to an observer. Though the noumenal holds the contents of the intelligible world, Kant claimed that man's speculative reason can only know phenomena and can never penetrate to the noumenon.

Kant was enormously influential in de-railing the philosophy of science. Prior to Kant, philosophers understood science in the natural way: science is about looking through the appearances in order to understand the hidden reality. However, Kant argued that this was an impossible task. All we have is appearances (phenomena), and we cannot look through them to get at the underlying hidden realities (noumena). He proposed that instead of studying the relation between appearances and reality, we should study the relationship between our thought process and the observations of the real world:

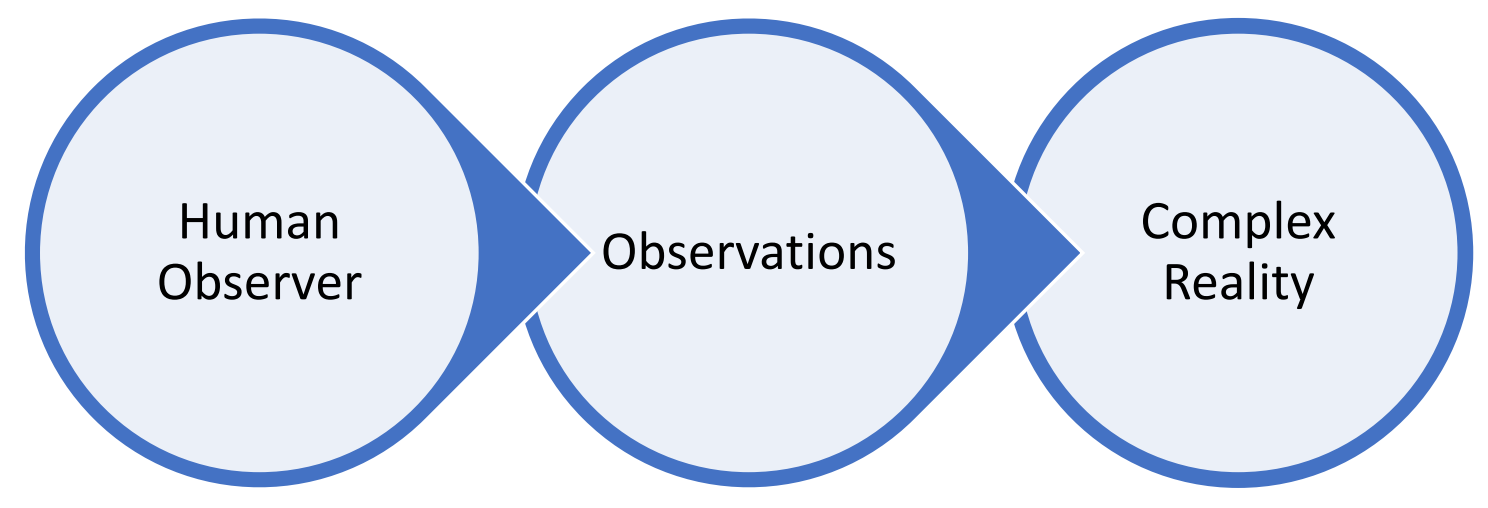

The Kantian separation between the models in our minds which explain the phenomena we observe, and the hidden reality was a fateful step towards the development of models completely de-linked from reality. To get a deeper understanding of Kant, we provide several arguments favoring his views. Think about how a simple computer camera looks at the world. The area being looked at by the camera is represented as a square two-dimensional patch which is say $1000 \times 1000$ pixels. At each pixel, if the camera detects light, it puts a 1 and if it does not, it puts a 0 . So, we end up with a picture of reality which is a $1000 \times 1000$ matrix of 1 's and 0 's. This is the OBSERVATION. Now how can we translate these observations into a picture of reality? This is the basic problem of computer vision - taking a stream of numerical inputs from the camera and translating it into a picture of reality. For example, a particular stream of 1 's and 0's may be interpreted as a picture of a tree, by a computer vision program. As human beings, we face a similar problem. We don't actually see the world out there. What we see is a reflection of the world within our eyes. Our minds process the image on our retina into a picture of the external reality. Before Kant, most people thought that the image in our minds matched the external reality. What Kant said was that we have no way of knowing this. We have no way of knowing the external reality. All we can see is the image of it on our retina, and the interpretation of it in our minds. A Kantian model, which we will label a mental model later, explains how we convert streams of 0 's and 1's into an image of reality.

For understanding the nature of models, we will need to keep these three things in mind. Reality generates observations. And our minds interpret observations as a picture of reality. Most of us think that the picture in our minds is exactly what the reality is. When I look at a tree, I do not say that my mind has interpreted an image on my retina as a tree. I say that there is a tree out there in external reality which I am seeing. However this is an over-simplified understanding. For example, when I see a mirage, I interpret the image on my retina as water, but in fact there 
is no water in external reality. Similarly, a fly has a compound eye, and sees the world in way which is very different from how we see it.
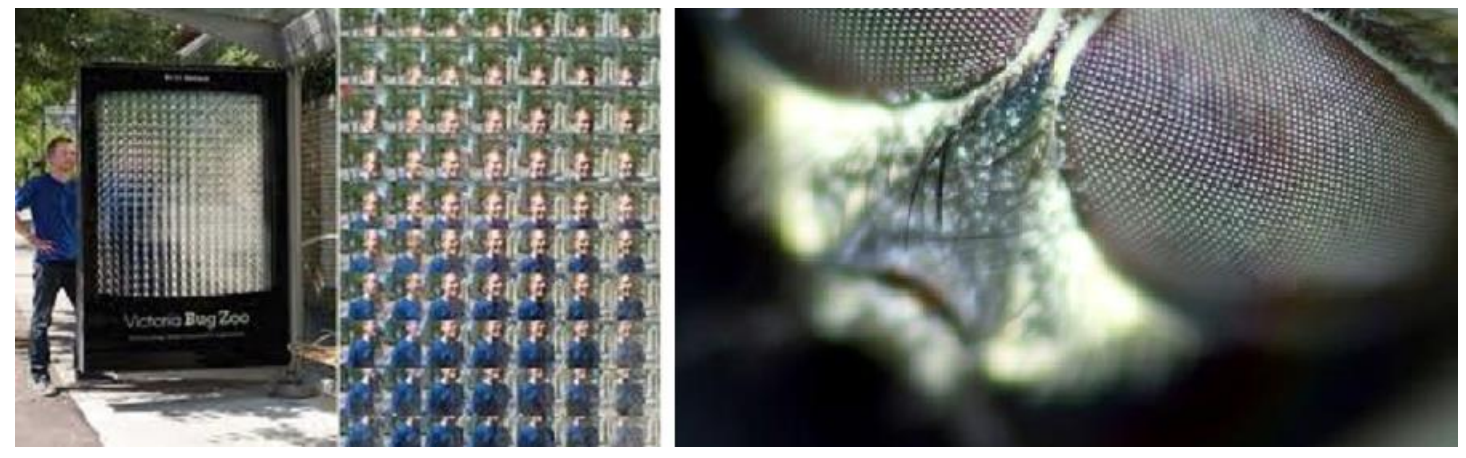

As opposed to Kant, traditional philosophy is concerned with the question of how the image we have formed in our mind (by interpreting the observations) relates to external reality (not to the bitstream of observations). Traditional philosophy would ask: which is the "correct" picture of external reality? What the fly sees or what we see? What Kant says is that there is no way to learn the answer to this question. We have no separate access to external reality apart from our observations. So instead of thinking about whether our mental pictures match true reality, we should think about how we process the stream of sensations we receive into an image (a model) of the world. Favoring Kant, evolutionary biologists argue that the picture that we see of the world tends to highlight those aspects which matter for our survival, and ignore or neglect those aspects which don't. This means that the representation of reality that is captured by our senses has less to do with the true external reality, and more to do with our own survival. The point of all this is that the naïve idea that what we see is just a true picture of reality is not necessarily correct.

This idea of Kant, that we can and should abandon looking for truth - the true picture of reality - has had a powerful effect on the philosophy of science today. Especially in economics, models that we build have no relation to reality. Rather the models in use are ways of organizing our own thoughts about reality. Robert Aumann expresses exactly this view about the nature of economic models:

"In my view, scientific theories are not to be considered 'true' or 'false.' In constructing such a theory, we are not trying to get at the truth, or even to approximate to it: rather, we are trying to organize our thoughts and observations in a useful manner."

Since we do not even try to get at the truth, there is no surprise if our models are hopelessly bad at approximating reality. Furthermore, the IDEA that we do not need to try to match reality, has led to the impossibility of correcting bad models to make them better. All that happens is that bad models are replaced by more complex models which are even worse.

\section{THREE TYPES OF MODELS}

When presenting the history of thought over the course of centuries, broad patterns and trends can only be seen if we allow the details to go somewhat out of focus. It is this kind of oversimplification that we undertake, in order to arrive at a simple trichotomy of models, which is not fully supported by a concrete and detailed examination of specific models, which often operate on more than one level. Nonetheless, this coarse-grained approach is helpful in 
understanding the answer to our main question: how did models divorced from reality become epistemologically acceptable?

In understanding the answer, it is important to start with the basic premise of Manicas (1987) that even though classical empiricism is not tenable as a philosophy of any science, some its central concepts became the main drivers of the methodology of modern economics. To understand this clearly, it is helpful to contrast empirical modes of understanding with realist modes. This section is based on the Introduction to Bhaskar (2008) "A Realist Theory of Science". In particular, we aim to explain Diagram 0.1 The Logic of Scientific Discovery, which diagrammatically distinguishes between (1) classical empiricism, (2) transcendental idealism, and (3) realism. This diagram from page 4 of Bhaskar (2008) is reproduced below:

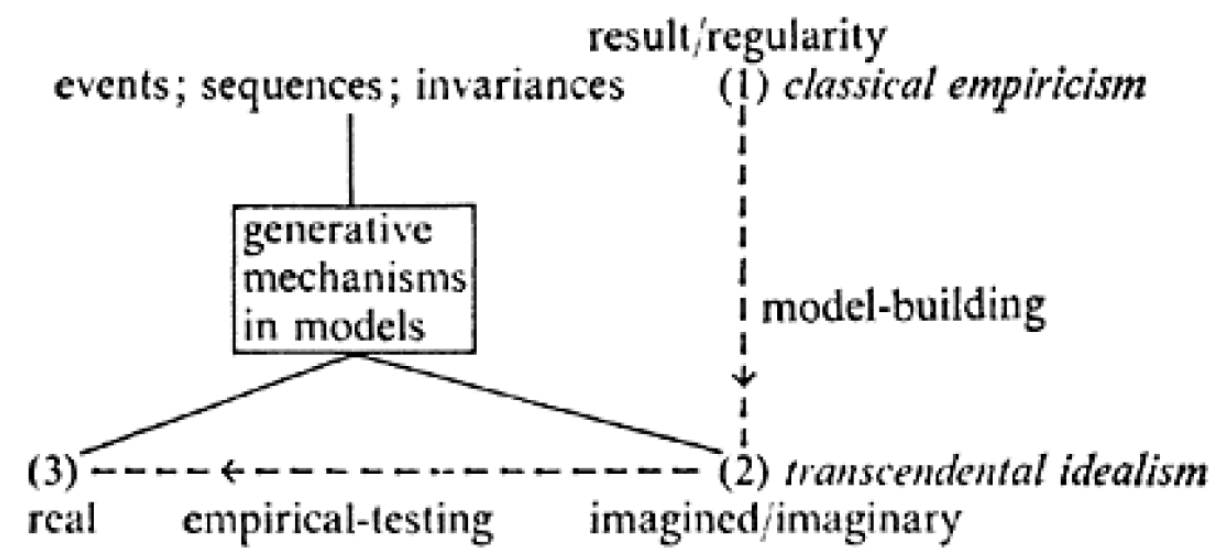

Diagram 0.1. The Logic of Scientific Discovery

We transform this diagram into three types of models for greater clarity.

For the purposes of our discussion, we can classify models into three different types, corresponding to the following diagram. The simplest type of model is a pattern in the data that we observe. A second type of model is a "mental model". This is a structure we create in our own minds, in order to understand the patterns that we see in the observations. The third type of model is a structure of the hidden real world, which generates the patterns that we see. Some examples will be helpful in clarifying these ideas about the typology of models.

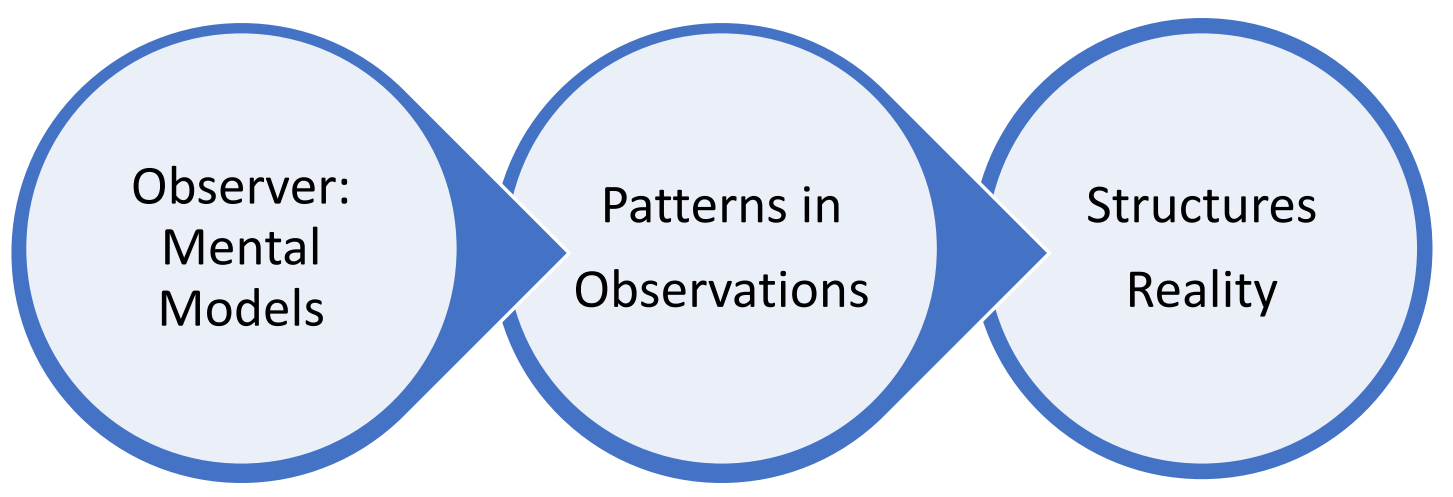




\subsection{Empirical Models}

The simplest kind of model consists of a pattern that we see in the observations. For example, if we see the sun rise every day for many years, this is a pattern in our experience. It leads us to conjecture the law that "the sun rises every day" - where the law extends beyond the range of our experience and observations. This is just a guess, based on patterns we see in the data. A regression model is an excellent example of an empirical model. It identifies patterns in the data, without any concern for the underlying realities. For example, a regression of Australian consumption per capita on China's GDP gives an excellent fit -

\section{Australian Consumption $=a+b$ Chinese GDP per capita $+\operatorname{error}\left(\right.$ high $R^{2}$, significant $t$-stats)}

This shows us that there is a pattern in the data - increases in China's GDP go along with increases in Australian consumption. The regression cannot answer the question of why there is this pattern. Any two series of data can display correlation - time series measuring numbers of sunspots sighted on the sun's surface can correlate with a wide variety of economic phenomena. The regression model which picks up this relationship has nothing to say about the reasons for the correlation. Given any kind of data, we can always find some regression relationship. Zaman (2012a) in "Methodological Mistakes and Econometric Consequences" presents many examples of strong regression patterns which are meaningless; for example:

Pakistani Consumption $=a+b$ Survival rate to age 65 of Females $+c$ Pollution Levels by Carbon Monoxide + error

In terms of classification - we can find many different kinds of patterns in any arbitrary set of data. Whether or not the patterns have meaning depend on the real-world processes which generate these patterns. This is something which Real Models are meant to explore.

\subsection{Real (Structural) Models}

The empirical models look at the surface structure, the appearances, the data that is based on observations. Structural models try to explore the hidden structure underneath the appearances. Consider for example a regression of consumption per capita on GNP per capita

$$
C=a+b Y+\varepsilon
$$

From the point of view of an empirical model, this is a pattern in the data. The names of the variables do not matter. If the consumption is Australian and the GNP is Chinese, the pattern is the same as if both variables belong to the same country. The names of the variable, and the relationships between them, matter only when we think about real structural models. For example, if we think that consumers earn incomes, and then spend some proportion of the income on consumer goods, this is a real structural relationship which explains why we see the pattern in the regression relationship. This structure justifies regressing Australian consumption on Australian GDP, but not on Chinese GDP. Also, if the determinants of GDP are the production processes, while consumption is determined by incomes, we cannot reverse the variables and run a regression of GDP on Consumption. Consumption is not a determinant of $G D P$. For an empirical model, $C$ on $Y$ and $Y$ on $C$ are the same patterns. Correlations are symmetric, but causal relationship are one directional. Real Structural Models attempt to find hidden real variables which cause the patterns that we see. For example, the tendency of 
consumers to consume a proportion of their income is the hidden cause for the surface data relationship between consumption and income within a country.

\subsection{Mental Models}

A pattern in the data is just a pattern - there is no explanation for it. This is the Baconian model of science. If we see a pattern in the data, we deduce that a law holds which generates this model. Any pattern that we see could be a law. A mental model imagines a structure of reality which could be an explanation for the reality. For example, an aggregate consumption function can arise from individual consumers who optimize utility derived from consumption bundles subject to budget constraints. It could also arise from consumers who make completely random consumption decisions, while staying within their budget. Any imaginary structure of reality which leads to observations which match what is actually observed, is a mental model.

Originally, mental models were designed by thinking about what the nature of hidden reality could be, and then trying to build a mental model to match that hidden structure. However, postKant, the main idea became different. Trying to match hidden reality was abandoned, and instead, the goal of the model building became to create a match to the observations. As a result, many concepts which are of vital importance to modelling reality were abandoned or misunderstood. For example, the idea of causation is of great importance in understanding reality. Rubbing a match against sulfur on the matchbox causes the match to burn. Learning about causation is of extreme importance in learning to navigate the world we live in. Our mental models are supposed to be representations of reality. For complicated historical reasons, economists FORGOT this basic idea about the nature of mental models, that they are supposed to capture the hidden real mechanisms which generate the observations. This has been an empiricist tendency starting from Hume. The idea that we cannot talk about hidden unknown realities has deep roots in Western intellectual rejection of God and religion; this angle is explored further in Zaman (2015).

As already discussed, Kant suggested that we can create a Copernican revolution in philosophy by changing the focus of our inquiry into the world. Philosophers have thought for ages about the problem of how we can find out if our mental models match the reality, the hidden unknown structures. But this is the WRONG question (according to Kant and the empiricists). We can never find out the answer, because the true hidden structures of reality will NEVER be observable. So, we should abandon this ancient question. Instead, we should focus on the question of how our mind organized the observations into a coherent picture of apparent reality (precisely as Aumann quoted earlier states). The diagram below shows the Kantian shift of focus. Traditional philosophy is concerned with the question of whether or not our mental models MATCH the hidden structures of the real world. This is the question of whether or not our models are TRUE. Kant and the empiricists said that this was impossible to know. We should only be concerned about whether or not our empirical models provide a good fit for the observations. So, the question itself was changed. Instead of asking if models match reality (and hence, whether or not they are TRUE), we ask whether the output of the models provides a match to the observations. This shift in concern about how models should be evaluated also encapsulates Friedman's methodological concern that models should predict well, and need have no match to reality.

The following diagram explains the current Empiricist views about models and reality. All that matters about mental models is that they should provide a match to the observations. It does not matter whether or not they match the true structures of reality which produce the observations. 


\section{Observations}

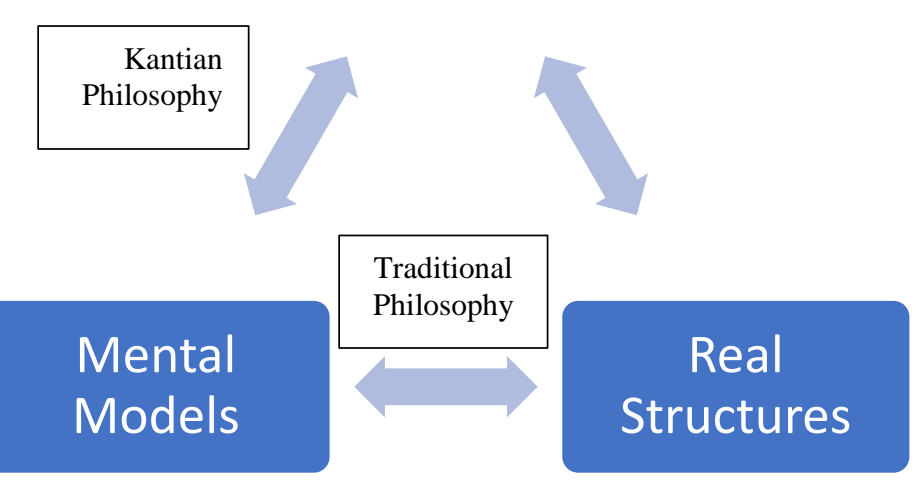

Due to the influence of Friedman's methodological essay - described in Maki (2009b) - this view has been widely accepted in Economics, and the methodology of modern Economics and Econometrics is based on this wrong idea about the nature of models. We now discuss this issue in the context of economics.

\section{ECONOMIC METHODOLOGY IS EMPIRICIST}

In the previous section, we discussed three types of models. The first type is based purely on patterns in observations, and does not attempt to go beyond what can be seen. This is an "observational" or Baconian model. The second type attempts to look through the surface and discover the hidden structures of reality which generate the observations we see. As Manicas (1987) remarks, it is only recently that a stable misconception of science, which persisted over centuries, has broken down. This has made it possible to develop realist philosophies of science. The previous section is based on Bhaskar (2008), but see also Manicas (2006) for another approach to a realist philosophy of science. The third type of model creates depth and structures in our minds which create the patterns we see in the observations. These may be called Kantian, or mental models. The Kantian perspective, reinforced by Max Weber's ideas about use of scientific methodology in social sciences, has been widely accepted in Economics. The methodology of modern Economics is largely Kantian (and Weberian), while Econometric models are largely Baconian. The key defect of both of these approaches is that they GIVE UP on the idea of finding the truth. We now discuss this issue in greater detail.

The deep and abiding influence of Milton Friedman (1953) on methodology in economic theory has been discussed at book length in Mäki (2009a). For our rough sketch, the main point we wish to extract is that Friedman recommends the abandonment of the search for truth: "Truly important and significant hypotheses will be found to have 'assumptions' that are wildly inaccurate descriptive representations of reality, and, in general, the more significant the theory, the more unrealistic the assumptions." What Friedman expresses, in ambiguous and inconsistent language, is the idea that an assumed structure of reality which is a mental model designed to match observations, need not match the true hidden structures of reality. All that matters is that observable implications of the model match our observed data. This idea is called "saving the appearances". For example, if we imagine that there is a heavenly sphere surrounding the earth and the moon is pasted on that sphere. Motions of the moon occur because 
of the rotations of the sphere. According the idea of "saving appearances", as long as the observed motion of the moon matches the predictions of our model, we need not be concerned with whether or not the heavenly sphere actually exists.

This is the fundamental methodological mistake at the heart of economics: the idea that we can make up any crazy model we like. As long as our models produce a match to the observations, it does not matter if we make wildly inaccurate assumptions. This has led to DSGE models, currently the dominant macroeconomic models, which have been called crazy by many authors. Economists make completely unrealistic assumptions without any discomfort, because of Friedman's idea that "wildly inaccurate" assumptions will lead to truly important and significant hypotheses. In a previous portion of this article, we documented the fact that economists are not bothered by conflicts between their models and reality. Below we provide quotes which document the crazy models that now dominate economics because of adherence to Friedman's Folly: the crazier the assumptions, the better the model.

Solow: Suppose someone sits down where you are sitting right now and announces to me that he is Napoleon Bonaparte. The last thing I want to do with him is to get involved in a technical discussion of cavalry tactics at the battle of Austerlitz. If I do that, I'm getting tacitly drawn into the game that he is Napoleon. Now, Bob Lucas and Tom Sargent like nothing better than to get drawn into technical discussions, because then you have tacitly gone along with their fundamental assumptions; your attention is attracted away from the basic weakness of the whole story. Since I find that fundamental framework ludicrous, I respond by treating it as ludicrous - that is, by laughing at it - so as not to fall into the trap of taking it seriously and passing on to matters of technique (Klamer \& Lucas, 1983).

Narayana Kocherlakota: Minneapolis Federal Reserve President (2010-2015) "The starting premise for serious models is that there is a well-established body of macroeconomic theory... My own view is that, after the highly surprising nature of the data flow over the past ten years, this basic premise of "serious" modeling is wrong: we simply do not have a settled successful theory of the macroeconomy." See Kocherlakota (2016).

Olivier Blanchard IMF Chief Economist (2010-2015), "DSGE models have come to play a dominant role in macroeconomic research. Some see them as the sign that macroeconomics has become a mature science, organized around a microfounded common core. Others see them as a dangerous dead end..." and "There are many reasons to dislike current DSGE models. First: They are based on unappealing assumptions. Not just simplifying assumptions, as any model must, but assumptions profoundly at odds with what we know about consumers and firms." See Blanchard (2016).

All of these authors are expressing the same complaint, in different forms. Mental Models are not Real Models. The only job mental models have to do is to produce a match to the observed data. Whether or not mental models are realistic has no bearing on whether or not they are good models. There is complete lack of concern about whether our mental models make assumptions which are realistic. Of central importance to the concerns of this paper is the weakness of Solow's (2010) attack on Lucas and Sargent's assumptions. After describing how these assumptions miss essential aspects of the economic system, he suggests that we dismiss them because they do not pass the "smell-test" ! He cannot attack their models for making wildly unrealistic assumptions, and for massive predictive failure, because his own widely popular and universally taught Solow growth model has the same defects! No wonder, defenders of the DSGE models simply respond to Solow by saying that these models smell good to them! 
The mystery of how models based on false assumptions can help us "understand" and "explain" the real world has been the subject of a long and complex methodological debate. For example, a leading methodologist, Mary Morgan (2012) writes that "Despite the ubiquity of modelling in modern economics, it is not easy to say how this way of doing science works. Scientific models are not self-evident things, and it is not obvious how such research objects are made, nor how a scientist reasons with them, nor to what purpose." In the "Explanation Paradox", Julian Reiss (2012) writes that it is widely accepted that: (1) economic models are false; (2) economic models are nevertheless explanatory; and (3) only true accounts explain. A whole subsequent issue of the Journal of Economic Methodology is devoted to the attempt to EXPLAIN how all THREE of Reiss' premises can be true. Alexandrova and Northcott (2013) - philosopher-outsiders - point out the obvious: economic models do not explain. However, this simple explanation falls on deaf ears; economists are too much addicted to meaningless mathematical models to realize that these models are mental structures which are "hanging in the air, having no contact with reality".

\section{BACONIAN SCIENCE VERSUS REAL STRUCTURES}

As we have discussed, models used in econometrics and economics can be classified into three broad categories. Because the methodology is never discussed explicitly, these distinctions are never discussed, resulting in extreme confusion. Below we discuss the difference between Baconian models of patterns in observations versus real structural models, as a preliminary step to discussing economic and econometric models.

The most primitive Baconian understanding of science is that science looks for patterns in observations. These patterns are the goal of scientific endeavor. When we find a pattern, that pattern is a potential scientific law. We can test the law by making predictions based on this law. If the prediction holds true, that means the pattern extends beyond the data that we see. It is a confirmation that there is an underlying law which generates the pattern. There are three basic principles of Baconian science

1. A scientific law is a pattern in the data, revealed by regression methods.

2. We can test scientific laws by prediction and forecasting - if the pattern holds beyond the observed range of data, then it is valid.

3. To "explain" an observation means making it part of a pattern; that is, observations which fit a regression model are explained by the regression.

The deep problems that emerge from taking models as just patterns in the data are explained in Zaman (2012a) "Methodological Mistakes and Econometric Consequences". Today, students of econometrics run regressions of anything on anything else, and make conclusions on the basis of the patterns shown by the data. It is a mistake to take an observed pattern as the scientific law. What we need is the underlying mechanism, often hidden, which explains the patterns we see. A REAL philosophy of science is based on REAL models. Real models postulate the existence of (hidden) entities and effects which cause the patterns that we see in the observations. For example, we see apples fall to the ground, and we postulate that there is a (invisible) force of gravity which the earth exerts on the apple to cause it to fall. This actually follows from a previous law of inertia which says that objects at rest will stay at rest unless a force acts on them. In a similar way, when we see consumers purchasing items using money 
earned by working, we assume that they have a (internal, unobservable) preference for the items they purchase, so they are prepared to work in order to get these objects. As opposed to the idea of Empirical or Observational Models, Real Models are characterized as follows:

Real structural models

1. Real Models postulate the existence of real objects (observable or not) with real properties, which create the patterns we see in the data. Scientific hypotheses concern these objects and effects, which describe the structure of hidden reality.

2. Often, hypotheses cannot be tested directly. We look for indirect ways of testing hypotheses regarding the existence of unobservable objects and effects. For example, gravity explains falling apples. We look for effects of gravity in other places, like tides, and planetary orbits. If one hypothesis explains a lot of different phenomena, it serves as an indirect confirmation.

3. Explanation is causal explanation. We say that what we observe is caused by hidden real objects and effects. The hidden preferences of the consumer lead him to choose object $X$ over object $Y$.

A simple way to understand the difference between Baconian models and Real Structural models is to think about models of consumer behavior. A real model is based on hypotheses (which may or may not be correct) about motivations for human behavior. For example, microeconomic theory assumes that human beings have utility functions: possession and utilization of consumer goods in different combinations gives them pleasure of varying degrees. This is a hidden structure, not observable. Based on this utility function, and on the budget constraint, consumers make their purchase decisions. So the observed pattern of consumer choices depends on the hidden structure of preferences and intensity of pleasure that we feel due to the consumption of commodities. An empirical model (or observational, Baconian model) cannot invoke hidden structures of reality. So, we are confined to look only at choices. We can observe choices, and impose certain rationality conditions such as the axioms of revealed preference. These axioms refer only to observed patterns of choices, and not to the underlying hidden preferences. There are patterns that we see in observed consumer choices, and these patterns ARE the scientific laws. It is not that these patterns can be explained with reference to the underlying hidden real structures.

\section{ECONOMETRIC MODELS: STRUCTURAL VERSUS REDUCED FORM}

In this section, we briefly consider the methodology of econometrics, which is based on Baconian or observational models. That is, econometric models tend to look only at what is available on the surface, as measured by observations, without attempting to discover the underlying reality which generates these observations.

The Structural Simultaneous Equations Models (SSEM) developed at the Cowles Foundation in mid-20th century, took causality seriously. The causal structures were derived from economic theories. Theory specified which variables were exogenous, and which variables were determinants of the endogenous variables. Equations were developed for the endogenous variables which represented the structure of the economy. To be more precise, regression equations were CAUSAL equations. Once this is understood, it is clear why $C=a+b Y$ (read as: $Y$ is a CAUSE of $C$ ) cannot be inverted to $Y=(1 / b) C-(a / b)$. The history of how this 
knowledge was lost, and how the causal structures implicit in the early days of SSEM were forgotten and abandoned, has been summarized in Chapter 5 of Pearl (2008). One of the key elements, also highlighted by Hoover (2004), is the lack of a mathematical language for expressing causality. Causal information was present, and used correctly, but never explicitly written in the equations. In particular, the "equal $(=)$ " sign has been held responsible for the damage. To better understand this, let us introduce the notation of $<=$ or $=>$ as a causal arrow, together with equality. Now the consumption equation could be written as: $C<=a+b Y+$ Error. All variables on the right-hand side of a causal equation must be causal determinants of the left-hand side. A causal equation is very different from a standard regression equation, and cannot be manipulated algebraically in the same way. It may be useful to highlight the causal factors by putting them in square brackets:

$C<=a+b[Y]+[$ Error $]$. Now the terms in square brackets are causal determinants of $C$. This equation cannot be re-written as $C<=a+[b Y+u]+[$ Error $-u]$ even though the two expressions on the RHS are algebraically equivalent. This is because $b Y+u$ would not be a causal determinant of $C$. Similarly, the status of the error term is clarified by putting it into square brackets. This is now a meaningful term, a causal factor, which means it must correspond to something which exists in the real world. Generally, people have a tendency to consume about $a+b Y$ from their incomes. Discrepancies from this level are CAUSED by other factors. The cumulative effect of all these ignored factors is measured by the error term. The error term is not a figment of imagination of the modeler, but a physical and measurable real-world variable, even though it is not directly observable because we are uncertain about the function $f(Y)$ which determines the consumption. In terms of the classifications given in Three Types of Models, Econometric Models can be classified as follows:

1. Real Models: These provide explicit models of the underlying, unobservable causal structures which generate the data. The original SSEM did aspire to this ideal, where the causal information was understood, and partially stated in the models, in the form of exogeneity, endogeneity, structural equations with inclusion and exclusion restrictions. However, the algebraic forms of equations did not explicitly and mathematically recognize the qualitative causal information. Partially because of this, but also due to other factors, causality was removed from the picture in interpretations of regression models. Present day Structural Equations Models are capable of carrying causal information, but are not used or interpreted in this way.

2. Observational Models: These are models which deal purely with observable probabilistic structures given in the data. The "Data-Generating Process" contains the probability information, but not the causal information. Sim's VAR models as originally formulated, are a perfect example of purely observational model. Sims discovered, to his chagrin, that even the simplest use of such models required input of causal information, which must be assumed, as it is not directly observable from statistical data distributions. This forced a reluctant move from VARS to SVARS, which incorporate minimal causal information in an ad-hoc an casual way. How causality enters data analysis is discussed in some detail in an elementary exposition of the Simpson's Paradox, given in Zaman and Salahuddin (2020).

3. Mental Models: Because it is impossible to interpret data without causal assumptions, all regression models make causal assumptions. However, these assumptions are implicit, arbitrary, and unrecognized, because they are not part of the explicit modeling 
process. As a result, models often carry absurd causal implications without any explicit recognition of this fact. A more detailed explanation is available in Zaman (2010).

To understand how explicit consideration of causal information affects our analysis of economic theories and corresponding regression models, we discuss some simple examples. Simple regression models ( $Y=a+b X+$ error $)$ between any two variables $X$ and $Y$ are examples of Baconian models; these are purely relationship between data points, which do not refer to the real-world processes which produced $X$ and $Y$. These models are often called reduced form models, because the underlying structures of external reality are reduced to the form in which they affect the observations. From the reduced form perspective, it does not matter if $Y$ is the consumption of Australia, and $X$ is the GNP of China, because only the data, and not its realworld interpretation matters. Similarly, the pattern in the data is reflected equally in regressions of $Y$ on $X$ and of $X$ on $Y$. It is only when we consider the structure of the real world that we can differentiate between the following three regressions:

1. Consumption of Australia regressed on GDP of Australia

\section{GDP of Australia regressed on Consumption of Australia}

\section{Consumption of Australia regressed on GDP of China}

The first regression is in structural form because it takes $G D P$ as exogenous and $C$ as being determined by GDP. This comes from knowledge of the real world which is not contained in the data. The second regression reversed the exogenous and endogenous variables. As reduced form equations, the two are equivalent, but as structural equations, the second is wrong. The mistake about exogeneity and endogeneity cannot be detected directly from the observed data. The third equation makes no sense from a structural point of view. In the external real world, we do not expect the GDP of China to have any strong causal effect on the consumption in Australia. However, when considered purely as a "reduced form" pattern in the data, the third equation turns out to be a very strong relationship; see Zaman (2010) for more details. As Baconian models, and as reduced forms, all three equations are equally acceptable. As structural form models, only the first one is acceptable.

Prior to the 1970's, econometric models were constructed as "structural" models. That is, the relationships among the observables were constrained by what was known about the hidden structures of external reality. For example, a consumption function related consumption to income and other determinants of consumer behavior. Consumption functions included variables known to affect consumption decisions, and excluded variables which were not relevant to consumption decisions. These were known as inclusion and exclusion restrictions in structural models. In addition, consumption was regressed in income, and not the other way around, because income is a determinant of consumption, and not the reverse. Similarly, the level of investment was taken to be a function of the interest rate, because it was thought that investors borrow money in order to make investments.

It is very important to understand that structural form of conventional econometric models is NOT what we have previously called REAL structural form models. The difference is that real structural models consider the HIDDEN structures of reality. For example, suppose there is a hidden variable $\mathrm{E}$ which is the expectations of the consumer about the future, which can be pessimistic or optimistic. Suppose this variable plays an important role in consumer decisions. A real structural model would take into account this hidden variable. Econometric structural 
models only look at the relationships between the observables. Suppose that $C$ is affected by $E$, and expectations $E$ are formed by looking at some variables $V$ which reflect the state of the economy. Then econometric structural models will remove the unobserved $E$ from the picture by linking consumptions to $V$. As opposed to this, recently introduced SEM (Structural Equation Models) techniques allow us to put unobservable factors into our models. These SEMs are very close to real structural models, in our terminology. The only difference is that loss of understanding about causality has led to loss of the causal interpretation these models, which has severely handicapped uses and functions of the SEM methodology; see Pearl (2008) for historical details.

In the 1970s OPEC placed an embargo on oil exports to Western countries which had supported Israel during the Yom-Kippur war. This generated huge shocks to the economies as oil prices doubled in a few months. As a result, nearly all econometric models failed badly to predict the consequences. These models may be roughly classified as "real models" based on causal information encapsulated via the informal Cowles Commission methodology. Predictive failure of these models led to two sets of critiques of econometric models, which went in opposite directions. One was the Lucas critique which led to the development of mental models, uncorrelated with reality. These eventually turned into the DSGE models which are the basic for macro policy today, even though they make assumptions wildly inconsistent with known realities. The other was the Sims critique, which led to abandonment of real causal structures, and a retreat to the surface patterns of observations as in empirical and Baconian models. We discuss this further in somewhat greater detail.

\subsection{Sims Critique: Atheoretical Var Models}

Sims thought that the structural assumptions which were reflected in econometric methodology of inclusions and exclusions, and endogeneity and exogeneity was the source of the failure. Structural models of the consumption function include GNP but exclude fertilizer prices because we believe that consumption decisions are strongly affects by the former but not by the latter. Instead, Sims argued that we should include ALL variables, because we did not know the hidden structures of the economy. Also, structural models take consumption as endogenous, because it is determined by GNP, but they take Investment as exogenous. Keynes argued that investors make decisions about how much to invest based on expectations about the future which are not anchored to any real variables (animal spirits, recently re-labelled as irrational exuberance). Sims argued that these decision about endogeneity of consumption and exogeneity of investment reflected inaccurate knowledge of the hidden underlying structures of the economy, and should be dropped. By dropping all structural restrictions, we come to a purely observational and empirical model, which only reflects patterns in the data, without any concern for the underlying economic structures. To illustrate the nature and consequences of VAR models, consider the following model, taken from an actual M.Phil. thesis of an economics student. Over a period $t=1,2, \ldots, T$ we collect data on four variables, with the goal of assessing the level of cotton productions. The true relationship would be nonlinear, but we can ignore this complication for our present discussion:
$W(t)=$ Fertilizer Used at time $t$,
$X(t)=$ Rainfall at time $t$,
$Y(t)=$ Acreage devoted to Cotton Production,
$\mathrm{Z}(t)=$ Annual Cotton Production, 
An econometric structural model would explain $Z(t)$ as a function of $W(t), X(t), Y(t)$, on the basis of our knowledge that the quantity of cotton produced would be related to the inputs used to produce it via the production function. A real structural model would dig deeper into the real processes by which cotton is produced. Rainfall effects would depend on the season in which the rainfall occurs, and the fertilizer efficiency would depend on many factors, observable and others. Structural models come from our knowledge of external reality. In contrast, Sims argues that since our structural knowledge is not reliable, we should use all variables as regressors for all variables. To be fair to Sims, he means to use this as a method for exploratory data analysis, as a preliminary step. However, even in this regard, examining purely data-based relationships will tend to highlight and pick up spurious relationships. For example, the VAR model that Sims methodology suggests here has four equations. Each variable is explained by lagged values of all the four regressors. For example, $W(t)$, is a function of $W(t-1), X(t-1), Y(t-1), Z(t-$ 1). This means that $W(t)$, fertilizer used at time $\mathrm{t}$, depends on the rainfall. Acreage, and Cotton production of the previous period. Similarly, Rainfall at time $t$ would depend on the amount acreage devoted to cotton in the last period, as well as $W(t-1), Z(t-1)$. These equations make no sense, because they ignore basic realities about the world we live in. Any numbers produced by these atheoretical VAR models are pure noise, random correlations between data which have no real causal mechanisms behind them.

An interesting note on VAR models is that there is nothing you can do with them. The main use of VAR models is to calculate impulse responses. That is, if you give a shock to one of the variables, how will the system respond. This is a causal question - if we make a change in amount of fertilizer applied, how will the other variables respond across time. It turns out that a purely a-theoretical approach is incapable of answering this question. This was not realized initially by Sims. To get answers to causal questions, we must put in assumptions about causal sequencing. Without any knowledge of how the four variables in the system are linked causally, we cannot calculate the impulse responses. In the four variable VAR system described above, we would find that increasing fertilizer can result in increased rainfall for the next few years, if we make arbitrary assumptions about causal sequencing. To get (barely) sensible results out of the VAR system, we must specify that rainfall, fertilizer, and acreage are exogenous and affect production, while cotton production does not causally affect the other three variables. These causal sequencing relationships come from our knowledge of external reality, and cannot be obtained from the data. When the causal sequencing is added to the VAR model, it is called a structural VAR model. This basically defeats the purpose of creation of the VAR model, which was to avoid "arbitrary" causal assumptions, and inclusion/exclusion assumptions. The problem is that the observations do not reveal the real structures which generate them. Calculations of impulse responses requires knowledge of this structure.

We have now discussed two types of econometric models based purely on patterns in observations. One of the types is the VAR models of Sims. These are basic Baconian models. VAR models only look at the patterns in the data, and do not incorporate any information about external reality. We have seen that this leads to absurd equations, which allow for the impact of fertilizer input on rainfall several years later. In contrast, the original regression models developed at the Cowles Commission (SSEM) incorporate information on underlying unobservable causal relationships. The SSEM models have the following three properties. The first property is a concession to the empiricist philosophy and overlaps with VAR methodology, while the second two show how real world unobservable information is reflected in the SSEM: 
1. Cowles Commission SSEM only model relationships between observable variables. However, unlike VAR models, structural equations are meant to be causal, reflecting true relationships between real world factors.

2. SSEM incorporate information about exogeneity and endogeneity which comes from knowledge about real world.

3. SSEM also incorporate inclusion and exclusion restrictions, which come from knowing about the causal relationships regarding which variables directly impact causally on others, and which do not have such causal effects. For example, we can exclude levels of fertilizer from the determinants of rainfall.

More recently, structural equations models (SEM) have been developed which improve on the SSEM by allowing unobservable factors to enter models, thereby creating the "real models" of our trichotomy. These have now come into vogue in nearly all social science areas except for econometrics and economics. These are very different from the SSEM because when we introduce unobservables into our models, then all estimation procedures must be changed. Even though these models represent real models, failure to interpret them as causal models within econometrics has led to limited use and considerable confusion about their meaning. Pearl (2008) provides some details about how statisticians inflicted causal blindness upon themselves.

The incorporation of unobservable variables and unobservable causal relations is both a weakness and a strength. It is a strength because it captures hidden structures of reality which are essential for understanding how the world works. It is a weakness because one can never arrive at certainty regarding these unobservables. Conjectures about unobservable variables and causal effects can receive confirmation from data, but can never be verified as being "facts" in the same sense that surface observations can be verified. As shown in Zaman and Salahuddin's (2020) discussion of the Simpson's Paradox, discovery of deeper real structures can always upset and reverse causal relationships which appear to be strongly confirmed by the data. It was this weakness which was attacked by Sims when he proposed dropping all unverifiable assumptions about unobservables to construct VAR models. The Lucas critique went in the opposite direction. Lucas attributed predictive failure of econometric models to their failure to consider the deeper structural relationships which drove the economy. Since these deeper relationships were unobservable, it was necessary to "imagine" them to create better models. While VAR models abandon reality by eliminating it, the mental models of Lucas abandon reality by substituting alternative realities, creating "post-real" models in the terminology of Romer (2016). This is discussed next.

\subsection{The Lucas Critique and Mental Models}

Lucas argued, correctly, that the hidden underlying deep structures of the economy were not captured by regression models based purely on observations. He argued that we could improve regression models, and prevent forecast failures, by capturing this hidden structure. However, the hidden structure he incorporated was not based on analysis and study of the external real world. Rather, he developed mental models in line with conventional economic methodology, which has been described in greater detail in Section 2 of this paper. Referring to DSGE models based on Lucas' approach, Solow cited in Zaman, 2018) writes that "A thoughtful person, faced with the thought that economic policy was being pursued on this basis, might reasonably wonder what planet he or she is on." Actually, Lucas has provided a detailed description of the 
planet on which mental models of economists are based. As described in his quote in section 2, this planet is populated solely by rugged individualist homo economicus, who cares only for consumption and nothing for social relationships, and calculates and maximizes his personal benefits to the last penny.

The problem does not lie with the bizarre assumptions, but with the failure to cross-check results with reality. Empirical evidence that individuals do not maximize utilities should lead to modifications of the models. Overwhelming evidence against utility maximization is gathered in a survey by Zaman and Karacuka (2012). In light of this evidence, it is necessary to revisit the artificial planet of the homo economicus, and repopulate it with humans who have more complex motives. However, economists simply ignore this evidence.

This process of cross-check and correction does not happen with models of economic theory. As Mäki (2018) has observed, economists produce substitute models. Even though methodological texts contain claims that model outcomes are cross checked against reality, this does not take place in practice. Instead of judging models by match to reality, models are judged on the basis of their conformity to aesthetic criteria, among which optimization and equilibrium are the most important. As the Sargent interview quoted in Section 2 shows, Lucas and associates responded to too many rejections of "good models" by the data, by stopping testing of the models. This is the key characteristic of mental models - they are never cross-checked against reality. This paper is motivated by the historical puzzle this poses. How did a methodology emerge which ignores this simple, basic, and common-sense requirement for good modeling?

\section{CONCLUDING REMARKS}

Friedman's (1953) defense of bizarre assumptions is actually valid within a correct scientific methodology. If we think that the main driver of economic behavior is utility maximization, it would be a good first step to construct a model based on these assumptions. We are now abstracting from complexity of human motivations. We want to see how much mileage we can get out this simplification. If we cross-check with actual reality and find this model adequate, then we have made a marvelous discovery - we do not lose much realism, but we gain substantially in understanding, by a massive simplification. On the other hand, if we find significant shortcomings in the match between model outcomes and reality, then we can introduce further complexity into the model to improve the match.

As we have seen, economists do not follow the Feynman principle that: "It doesn't matter how beautiful your theory is, it doesn't matter how smart you are. If it doesn't agree with experiment, it's wrong". This paper is motivated by the desire to understand how this is possible? How did a methodology emerge which claims to be scientific and yet allows one to ignore conflicts between outcomes of theory and the data? The solution to this puzzle lies in the empiricist philosophy which led to vast misunderstanding of science that persists to this day. In this paper, we have provided a sketch of how the Kantian disconnect between observables and reality translated into a misunderstanding of science which has never been corrected. This misunderstanding, which has evolved over time in many different ways, is responsible for a methodology which produces models divorced from reality.

The abandonment of efforts to match real structures has led to disaster, as models of economic theory have grown progressively distant from reality. Attempts to fix the problem have failed to address the cause. Economists look at bad models, and say we should replace these by better 
models. But the process by which models are evaluated, the underlying methodology, is not examined. The real problem lies much deeper than bad models and ludicrous assumptions. Bad assumptions would quickly be replaced by better ones if the methodology insisted on correction of models to match reality. The real problem is the lack of a progressive methodology. When our mental models are attempts to approximate reality, then, when they fail, we try to improve the match to reality. Our models become better as approximations to the hidden structures of reality. However, when we abandon efforts to match reality, our mental models can become progressively worse as approximations to reality while becoming better at providing a match to observations. This is precisely what happened to Ptolemaic astronomy. The original assumption of planets attached to orbiting heavenly spheres failed to match observations. So small spheres affixed to the big spheres were introduced. Similar ad-hoc corrections improved the fit to observed orbits, but made the models wildly inaccurate as approximations to the real structure of underlying reality.

The problem can be fixed only if we adopt a realist philosophy of science. Critical realism offers an extremely useful alternative to current economic and econometric methodology. A realist philosophy has the possibility of learning from experience. Even if we start with ridiculous assumptions, we will modify them in face of empirical evidence to the contrary. In complete contrast, economists stubbornly stick to assumptions known to be false because the standard methodology says that false assumptions are not a problem for models. There is no hope for progress in economics until we abandon Friedman's methodological prescriptions according to which the more ludicrous our assumptions, the better our model.

\section{REFERENCES}

Alexandrova, A. and R. Northcott (2013). It's just a feeling: why economic models do not explain. Journal of Economic Methodology, 20 (3), 262-267.

Bergmann, B. (2007). Needed: a new empiricism. The Economists' Voice, 4 (2), 1-4.

Bhaskar, R. (2008). A Realist Theory of Science. London and New York: Routledge.

Blanchard, O. (2016). Do DSGE models have a future? Revista de Economía Institucional, 18 (35), 39-46.

Cooter, R. and P. Rappoport (1984). Were the Ordinalists wrong about welfare economics? Journal of Economic Literature, 22 (2), 507-530.

Evans, G. W. and S. Honkapohja, (2005). An interview with Thomas J. Sargent. Macroeconomic Dynamics, 9 (4), 561-583.

Friedman, M. (1953). The methodology of positive economics. In M. Friedman, Essays in Positive Economics. Chicago: University of Chicago Press.

Hands, D. W. (2012). The positive-normative dichotomy and economics. Handbook of the Philosophy of Science, 12, 219-239.

Hausman, D., M. McPherson and D. Satz (2016). Economic analysis, moral philosophy, and public policy. Cambridge University Press. 
Hoover, K. D. (2004). Lost causes. Journal of the History of Economic Thought, 26 (2), 149164.

Klamer, A. and R. E. Lucas (1983). Conversations with economists: New classical economists and their opponents speak out on the current controversy in macroeconomics. Rowman \& Littlefield.

Kocherlakota, N. (2016, July 17). Toy Models. Retrieved March 11, 2020, from https://t.co/8dS85Nlpg9

Mäki, U. (2002). Fact and fiction in economics: models, realism and social construction. Cambridge University Press.

Mäki, U. (2009a). The methodology of positive economics: Reflections on the Milton Friedman legacy. Cambridge University Press.

Mäki, U. (2009b). Reading the methodological essay in twentieth-century economics: map of multiple perspectives. The Methodology of Positive Economics, 47.

Mäki, U. (2018). Rights and wrongs of economic modelling: refining Rodrik. Journal of Economic Methodology, 25 (3), 218-236.

Manicas, P. (1987). A history and philosophy of the social sciences. Oxford: Basil Blackwell.

Manicas, P. T. (2006). A realist philosophy of social science: Explanation and understanding. Cambridge University Press.

Morgan, M. S. (2012). The world in the model: How economists work and think. Cambridge University Press.

Pearl, J. (2008). Causality: models, reasoning, and inference (2. ed.). Cambridge University Press.

Putnam, H. (2002). The collapse of the fact/value dichotomy and other essays. Harvard University Press.

Reiss, J. (2012). The explanation paradox. Journal of Economic Methodology, 19 (1), 43-62.

Robbins, L. (1932). An essay on the nature and significance of economic science. London: Macmillan.

Rodrik, D. (2015). Economics rules: The rights and wrongs of the dismal science. WW Norton \& Company.

Romer, P. (2016). The trouble with macroeconomics. The American Economist, 20, 1-20.

Solow, R. (2010). Building a Science of Economics for the Real World. In House Committee on Science and Technology Subcommittee on Investigations and Oversight.

Suppe, F. (2000). Understanding scientific theories: An assessment of developments, 19691998. Philosophy of science, 67, 102-115.

Willard, V. O. (1963). Two dogmas of empiricism. In M. Richard, Meanings as Species. 
Zaman, A. (2010). Causal Relations via Econometrics. International Econometrics Review, 2 (1), 36-56.

Zaman, A. (2012a). Methodological Mistakes and Econometric Consequences. International Econometric Review, 4 (2), 99-122.

Zaman, A. (2012b). The Normative Foundations of Scarcity. Real-World Economics Review, 61 (26), 22-39.

Zaman, A. (2015). Deification of Science and Its Disastrous Consequences. International Journal of Pluralism in Economics Education, 6 (2), 181-197.

Zaman, A. (2018, July 26). Quotes Critical of Economics. Retrieved March 01, 2020, from WEA Pedagogy Blog Post.

Zaman, A. (2020, February 19). Facts and Values: Distinction or Dichotomy? Retrieved March 01, 2020, from WEA Pedagogy Blog Post.

Zaman, A., \& Karacuka, M. (2012). The Empirical Evidence Against Neoclassical Utility Theory: A Review of the Literature. International Journal for Pluralism and Economics Education, 3 (4), 366-414.

Zaman, A., \& Salahuddin, T. (2020). Causality, Confounding, and Simpson's Paradox. International Econometrics Review, 12 (1). 